\title{
Molluscum Contagiosum Involving an Epidermoid Cyst - A Rare Association and Potential Source of Clinical Misdiagnosis
}

\author{
Prithwijit Ghosh, ${ }^{1}$ Kaushik Saha ${ }^{2}$ \\ 'Neon Lab, Kolkata, ${ }^{2}$ Department of Pathology, IPGME \& R, Kolkata, India.
}

\section{ABSTRACT}

Molluscum contagiosum (MC) is a viral infection of skin and mucous membrane commonly affecting the adolescents and young adults. Extensive lesions are usually common in immunocompromised patients. We herein report a rare case of molluscum contagiosum in an epidermoid cyst (EC) in a 24-year-old immunocompetent male. The provisional clinical diagnosis was inflammed epidermoid cyst or lipoma. On histopathological examination, the lesion displayed a unilocular epidermoid cyst in deep dermis, the lining of which was infected by molluscum contagiosum virus with characteristic inclusions. The overlying epidermis was absolutely normal having no attachment with the cyst.

Keywords: epidermoid cyst; molluscum body; molluscum contagiosum.

\section{INTRODUCTION}

Molluscum contagiosum (MC) is a poxvirus infection of the skin and mucous membranes caused by a virus in the subgenus Molluscipoxvirus, which comprises four genetically distinct viral subtypes. ${ }^{1}$ The disease is more commonly found among adolescents and young adults. People with immunocompromised status are frequently affected by this virus. The lesions of $\mathrm{MC}$ have a predilection for the head and neck region, the flexural areas and the genitalia. ${ }^{2}$ Extensive lesions can occur in immunocompromised patients, particularly those with AIDS. ${ }^{3}$ However, the occurrence of $M C$ in an epidermoid cyst (EC) is a rare phenomenon. ${ }^{4}$ We are presenting such a rare case of $\mathrm{MC}$ affecting the lining of an EC in an immunocompetent patient that led to a clinical misdiagnosis.

\section{CASE REPORT}

A 24 year old male presented with a four month history of an itchy, skin-colored, soft to firm nodule gradually increasing in size in front of right auricle measuring 2.7 $\times 2.4 \mathrm{~cm}^{2}$ (Figure 1). The lesion was mildly tender, soft to firm on palpation. There was no erythema, surface scaling, punctum, umbilication or erosion over the swelling. No similar lesions were found elsewhere after meticulous examination. No known history of immunosuppression due to any disease or drug intake was obtained. The clinician suggested the provisional differential diagnosis of inflammed EC or lipoma. The lesion was excised under local anesthesia. The formalinfixed specimen was routinely processed and embedded in paraffin. Sections were cut at $5 \mu \mathrm{m}$ thickness and stained with Hematoxylin and Eosin ( $\mathrm{H}$ and $\mathrm{E})$ stain.

The sections displayed a unilocular cyst in the deep dermis with no visible connection with the overlying epidermis (Figure 2a). The cyst was lined by hyperplastic squamous epithelium showing cytopathic changes characteristic of MC (Figure 2b). There were plenty of eosinophilic cytoplasmic inclusion bodies pushing the hyperchromatic and shrunken nuclei

Correspondence: Dr. Kaushik Saha, Department of Pathology, IPGME \& R, Kolkata, India. Email: drkaushik.saha@yahoo.com, Phone: +919230630451 . 
against the cell membrane and progressively enlarging towards the center of the cyst (Figure 2c). Basophilic inclusions were also noted at the level of granular layer producing condensation of kerato-hyaline granules. These molluscum bodies were extruded along with keratinous debris in the center of the cyst. In addition to abundant molluscum bodies, plenty of loose lamellar keratin flakes were observed inside the cyst (Figure $2 d)$. Few chronic inflammatory cells were also noted in the background. The overlying epidermis was normal having no cytopathic effect of MC.

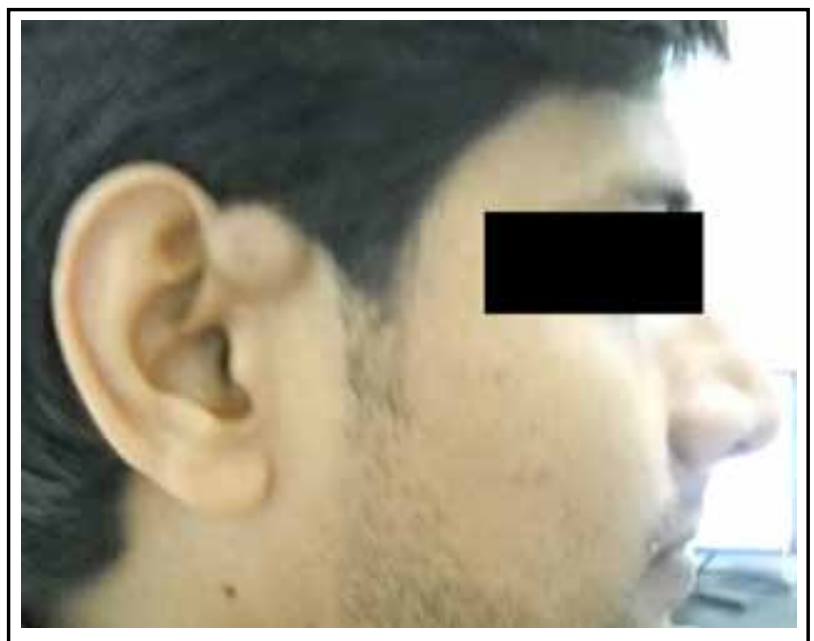

Figure 1. Single skin colored soft to firm nodule in front of right auricle.

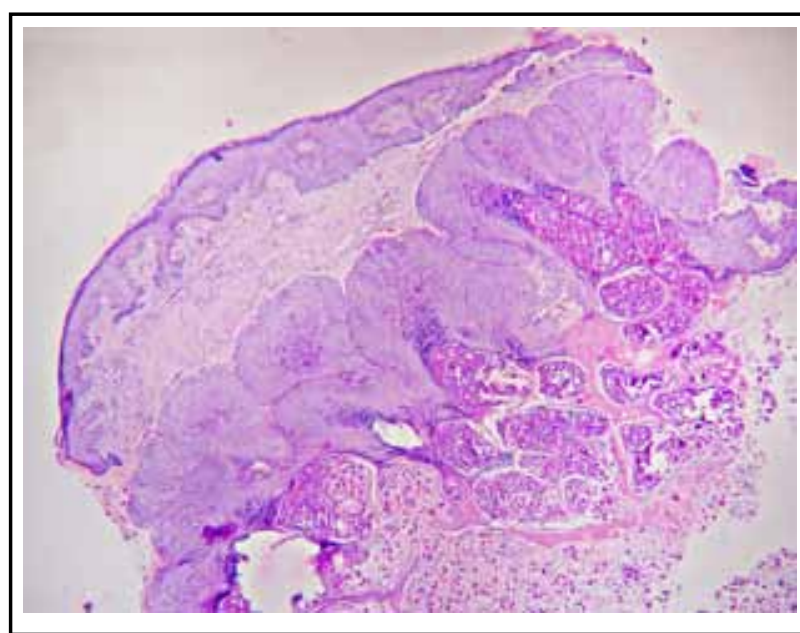

Figure 2(a). A scanning view of the molluscum contagiosum in epidermoid cyst in the deep dermis with normal overlying epidermis $(H$ and $E, \times 40)$.

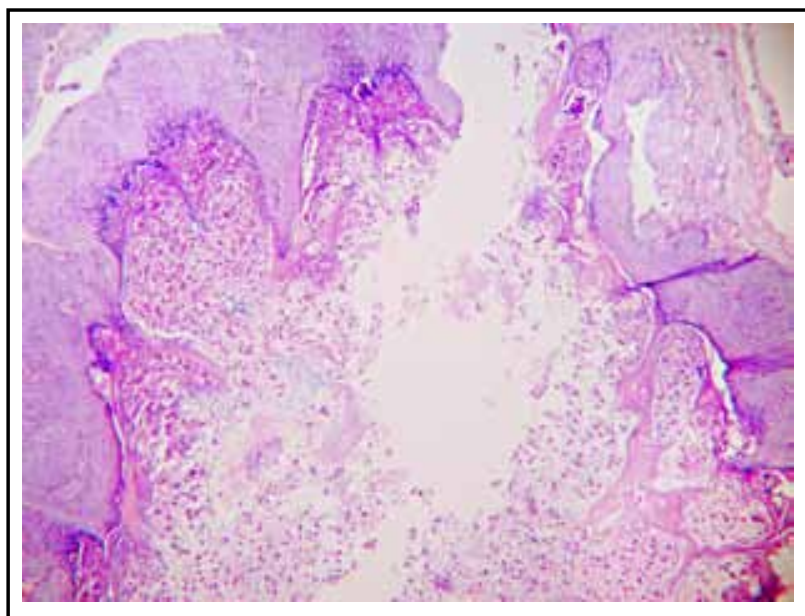

Figure 2(b). Unilocular epidermoid cyst with crateriform lesions lined by hyperplastic squamous epithelium ( $H$ and $E, \times 40)$.

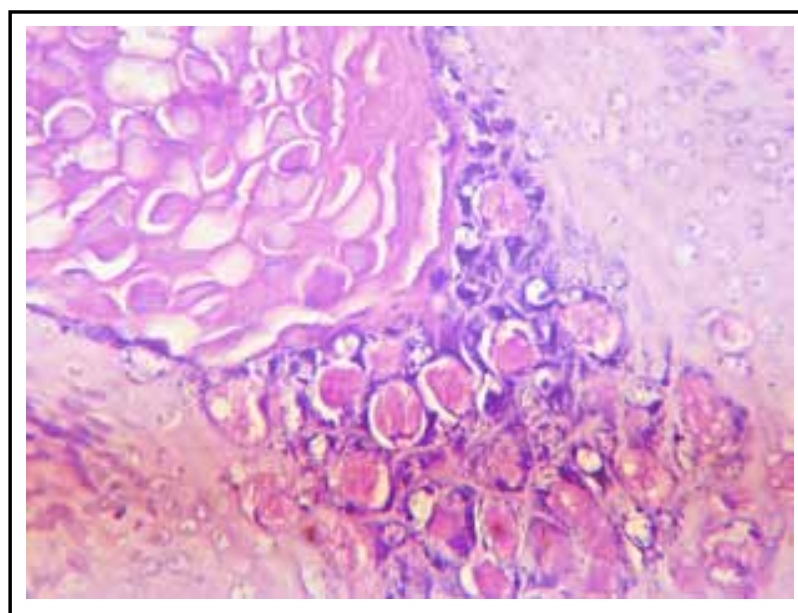

Figure 2(c). Large cytoplasmic inclusions in keratinocytes with peripheralized shrunken nuclei $(H$ and $E$, $\times 400)$.

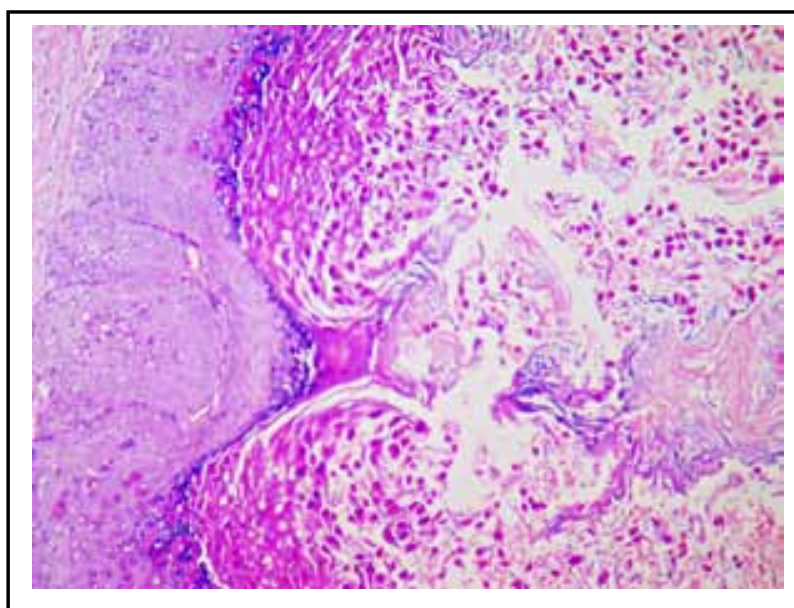

Figure 2(d). Cyst containing plenty of molluscum bodies and loose lamellar keratin (H and $E, \times 100)$. 


\section{DISCUSSION}

Less than twenty cases of MC in EC have been reported in the literature. ${ }^{5-8}$ Various hypotheses have been proposed to describe the pathogenesis of these occurences, including coinoculation of $\mathrm{MC}$ virus at the time of development of the EC, the invasion of virus into a preexisting cyst or simple dilatation of pilar infundibula by cornified cells and molluscum bodies. ${ }^{3,6,7}$

Few literature have described $M C$ in $E C$ among HIV patients. ${ }^{5,9}$ Aldabagh et al, ${ }^{5}$ even demonstrated associated xanthogranulomatous reaction with pale and foamy histiocytes and admixed lymphocytes. Most ECs demonstrate a small opening to the skin surface through which MC virus can communicate from the neighboring skin into the epidermoid cyst and facilitate extension of virus from an infected epidermoid cyst to the adjacent skin. ${ }^{7}$ Though the MC is usually a self-limiting benign lesion, the duration of spontaneous resolution varies from months to years. Moreover recurrences have been reported often in severely immunocompromised cases and even sparsely with immunocompetent status. Besides watchful waiting for spontaneous resolution, destructive therapy like curettage or cryotherapy, immunomodulators like imiquimod and antiviral therapy may be necessary in some cases of MC. ${ }^{10}$

In the present case, there was no opening or umbilication over the lesion that led to the initial clinical misdiagnosis. Finally with proper clinicopathological corroboration the correct diagnosis was arrived at. Whether simple excision, as considered enough for a simple EC, is adequate or not in cases similar to the present one needs further research work to throw light into this matter. Thus in the present case, the correct diagnosis of $\mathrm{MC}$ in this particular clinical setting was vital.

\section{REFERENCES}

1. Dohil MA, Lin P, Lee J, Lucky AW, Paller AS, Eichenfield LF. The epidemiology of molluscum contagiosum in children. J Am Acad Dermatol. 2006;54:47-54.

2. Prieto-Granada CN, Lobo AZC, Mihm MC., Jr.Skin infections. In: Kradin RL, editor. Diagnostic Pathology of Infectious Disease. Philadelphia, PA: Saunders Elsevier; 2010. p. 519-616.

3. Weedon D. Viral diseases. In: Weedon D, editor. Weedon's Skin Pathology. $3^{\text {rd }}$ ed. Edinburgh, UK: Churchill Livingstone Elsevier; 2010. p. 607-31.

4. Ueyama Y, Osamura Y, Shimamura K, Nishimura M, Machida S, Tamaoki N. Molluscum contagiosum occurring in an epidermal cyst on the eyelid. Light and electron-microscopic studies with literature review. Acta Pathol Jpn. 1985;35:193-8.

5. Aldabagh B, Ly MN, Hessel AB, Usmani AS. Molluscum contagiosum involving an epidermoid cyst with xanthogranuloma-like reaction in an HIV-infected patient. J Cutan Pathol. 2010;37:282-6.
6. Kanitakis J. Molluscum contagiosum in an epidermoid cyst. Am J Dermatopathol. 2011;33:638-40.

7. Phelps A, Murphy M, Elaba Z, Hoss D. Molluscum contagiosum virus infection in benign cutaneous epithelial cystic lesions-report of 2 cases with different pathogenesis? Am J Dermatopathol. 2010;32:740-2.

8. Basak K, Basak PY, Karadayi N. Molluscum contagiosum in multiple epidermal cysts in an immunocompetent patient. Saudi Med J. 2013;34:319-20.

9. Smith KJ, Yeager J,Skelton H. Molluscum contagiosum: its clinical, histopathologic, and immunohistochemical spectrum. Int J Dermatol. 1999;38:664-72.

10. Mathes EF, Frieden IJ. Treatment of molluscum contagiosum with cantharidin: a practical approach. Pediatr Ann. 2010;39:124-8. 